\title{
Manifesto de Curitiba: pela Prevenção Quaternária e por uma Medicina sem conflitos de interesse
}

The Curitiba Manifesto: for the Quaternary Prevention and for a Medical Practice without conflicts of interest

Manifiesto de Curitiba: por la Prevención Cuaternaria e por una Medicina sin conflictos de intereses

André Luiz da Silva. Pontifícia Universidade Católica do Rio Grande do Sul (PUC-RS). Porto Alegre, RS, Brasil. andreldsilva@me.com (Autor correspondente)

Derelie Mangin. McMaster University. Toronto, Canadá. mangind@mcmaster.ca

Miguel Pizzanelli. Unidad Docente Asistencial Rural de Florida. Florida, Uruguai. miguelpizzanelli@gmail.com

Marc Jamoulle. Department of Family Practice, University of Liege. Belgium. marc.jamoulle@doct.ulg.ac.be

Hamilton Lima Wagner. Secretaria Municipal de Saúde de Curitiba. Curitiba, PR, Brasil. hamiltonw@uol.com.br

Dijon Hosana Souza Silva. Grupo de Trabalho de Prevenção Quaternária da Sociedade Brasileira de Medicina de Família e Comunidade (SBMFC).

Ilhéus, BA, Brasil. dijonhosana@hotmail.com

Rodrigo Luciano Bandeira de Lima. Secretaria Municipal de Saúde de Recife. Recife, PE, Brasil. rblima@gmail.com

Sandro Rodrigues Batista. Universidade Federal de Goiás (UFG). Goiânia, GO, Brasil. sandrorbatista@gmail.com

Juliana Oliveira Soares. Secretaria de Estado de Saúde do Distrito Federal. Brasília, DF, Brasil. Juliveirasoares@gmail.com

Ana Duboc Rochadel. Secretaria de Estado de Saúde do Distrito Federal. Brasília, DF, Brasil. anarochadel@gmail.com

Raquel Vaz Cardoso. Departamento de Atenção Básica do Ministério da Saúde (DAB/MS). Brasília, DF, Brasil. raquelvc.mfc@gmail.com

Eno Dias de Castro Filho. Serviço de Saúde Comunitária do Grupo Hospitalar Conceição (SSC/GHC), Porto Alegre, RS, Brasil. enofilhouol@gmail.com Luciano Nunes Duro. Universidade de Santa Cruz (UNISC). Santa Cruz do Sul, RS, Brasil. Iduro2009@gmail.com

Tarso Teixeira. Fundação Universitária de Rio Grande (FURG). Rio Grande, RS, Brasil. tarso.teixeira@terra.com.br

Guilherme Ramos Sens. Secretaria Municipal de Saúde de Ibicaré. Ibicaré, SC, Brasil. guiramossens@gmail.com

Waldomiro Reis Júnior. Prefeitura de Belo Horizonte. Belo Horizonte, MG, Brasil. waldomiroreis@gmail.com.br

Pelo Grupo de Trabalho de Prevenção Quaternária da Sociedade Brasileira de Medicina de Família e Comunidade

Nós, médicos de família e comunidade reunidos no I Seminário Brasileiro de Prevenção Quaternária, trazemos o seguinte manifesto em prol de uma Medicina isenta de conflitos de interesses e imbuída de profissionalismo no seu sentido mais pleno. Estamos baseados nos seguintes pressupostos:

\section{Código de Ética Médica ${ }^{1}$}

II - O alvo de toda a atenção do médico é a saúde do ser humano, em benefício da qual deverá agir com o máximo de zelo e o melhor de sua capacidade profissional;

IV - Ao médico cabe zelar e trabalhar pelo perfeito desempenho ético da Medicina, bem como pelo prestígio e bom conceito da profissão;

V - Compete ao médico aprimorar continuamente seus conhecimentos e usar o melhor do progresso científico em benefício do paciente;

IX - A Medicina não pode, em nenhuma circunstância ou forma, ser exercida como comércio;

Como citar: Silva AL, Mangin D, Pizzanelli M, Jamoulle M, Wagner HL, Silva DH et al. Manifesto de Curitiba: pela Prevenção Quaternária e por uma Medicina sem conflitos de interesse. Rev Bras Med Fam Comunidade. 2014;9(33):pp-pp. Disponivel em http://dx.doi.org/10.5712/ rbmfc9(32)1006 
XIV - O médico empenhar-se-á em melhorar os padrōes dos serviços médicos e em assumir sua responsabilidade em relação à saúde pública, à educação sanitária e à legislação referente à saúde;

XXIII - Quando envolvido na produção de conhecimento científico, o médico agirá com isenção e independência, visando ao maior benefício para os pacientes e a sociedade;

É vedado ao médico:

Art. 68. Exercer a profissão com interação ou dependência de farmácia, indústria farmacêutica, ótica ou qualquer organização destinada à fabricação, manipulação, promoção ou comercialização de produtos de prescrição médica, qualquer que seja sua natureza.

É vedado ao médico:

Art. 104. Deixar de manter independência profissional e científica em relação a financiadores de pesquisa médica, satisfazendo interesse comercial ou obtendo vantagens pessoais.

\section{Conceito de profissáo enquanto compromisso com valores profissionais}

Uma profissão é:

1. livre da influência do comércio e do Estado e

2. responsável pela sua própria educação e estrutura de conhecimento²

\section{E conceito de Prevenção Quaternária ${ }^{3}$}

"Ação feita para identificar pacientes em risco de sobremedicalização, para os proteger de mais intervençóes em saúde e para lhes sugerir intervençôes eticamente aceitáveis" (Adaptado de Jamoulle e Roland, 1995)

Portanto, nós, médicos defensores da prevenção quaternária em qualquer nível de atenção à saúde, defendemos os princípios bioéticos em prol do melhor e do mais aceitável para a população:

- Não-maleficência: partindo do pressuposto hipocrático de "em primeiro lugar não causar dano" (primum non nocere), sempre levaremos em conta o fato de que, quanto maior o risco de causar dano, mais embasado cientificamente e isento de interesses diversos do científico deve ser o procedimento em questáo para que este possa ser considerado um ato eticamente aceitável, mesmo que para tal se faça necessário questionar aspectos metodológicos e conflitos de interesses em protocolos e diretrizes (muitas destas tidas como conhecimento inquestionável, porém gerado sob uma perspectiva comercial), sempre pautados na melhor evidência cientifica isenta disponível, e evitando ao máximo a "Disease Mongering" (promoção da doença), a transformação de fatores de risco e eventos fisiológicos em doenças, a medicalização desses eventos ou o excesso diagnóstico, que podem por a pessoa em risco de estigmas e danos posteriores.

- Beneficência: pensando no melhor para o paciente (do grego pathe - sentimento -, com seus desdobramentos no latim patientem - aquele que sofre -, e pax-paz, paciência), estaremos em busca sempre das melhores e mais adequadas evidências científicas livres de conflitos de interesses para promover a saúde das doenças, com o mínimo de intervençôes possíveis. Significa que buscaremos desenvolver açôes proativas "para o bem do paciente", livres de influências externas, lembrando que condutas expectantes ou mesmo a desprescrição também são açóes proativas para o benefício das pessoas. E o efeito benéfico envolve também proteger as pessoas de informações inadequadas e reduzir a angústia causada pela Disease Mongering, além de fornecer informaçóes adequadas a essas pessoas para que elas mesmas pesem riscos e benefícios e tomem suas decisóes por meio da persuasão puramente profissional-relacional, visando ao melhor resultado possível para aquela pessoa.

- Autonomia: a autonomia ou autodeterminação envolve dois aspectos durante o estabelecimento da relação médicopaciente:

1. capacidade para atuar deliberadamente, o que envolve razáo e discernimento para decidir entre as alternativas que lhe são apresentadas e

2. liberdade, no sentido de estar livre de qualquer influência controladora para a emissão de um posicionamento. ${ }^{4}$ 
Portanto, é nossa premissa empoderar a população com as informaçôes mais confiáveis possíveis para a tomada de decisão conjunta diagnóstica ou terapêutica, sem manipulação nem coerção, mas com a avaliação correta de riscos e benefícios, em especial naqueles procedimentos onde ainda há fraco embasamento cientifico e onde há fortes influências de indústrias farmacêuticas ou de produtos médicos-hospitalares, e mesmo de corporaçóes com interesses mercantilistas, indo de encontro aos princípios aqui discorridos. É nossa premissa também tornar as pessoas conhecedoras para uma melhor tomada de decisão, já que o conhecimento, e não a desconfiança, é a melhor ferramenta para a prevenção quaternária. ${ }^{5}$

- Justiça: também é nossa premissa, enquanto promotores e defensores da prevenção quaternária, a luta pelo acesso equânime, justo e apropriado aos recursos em saúde, denunciando a mercantilização da saúde e o uso do sistema sanitário para finalidades diversas do benefício das pessoas, reforçando que justiça e acesso nem sempre estáo relacionados às "últimas novidades tecnológicas em saúde".

Nós não cuidamos de órgãos. Nós não promovemos doenças. Nós não superestimamos fatores de risco. Nós cuidamos de pessoas, e pessoas não são números, escores, fatores de risco e nem meros objetos de intervençóes. Nós somos cautelosos com resultados surpreendentes de publicações científicas, pois dados podem ser manipulados para diagnosticar sintomas menores ou fatores de risco e assim reduzir os pontos de corte do diagnóstico de uma doença, bem como para criar "pré-doenças", aumentar o espectro de medicalização e gerar de forma perniciosa lucros para a indústria farmacêutica. ${ }^{6}$ Nós respeitamos o tempo na ciência e respeitamos a linha do tempo da relação médico-paciente, pois o aspecto relacional na atenção em saúde sempre prevalecerá sobre o aspecto populacional.

Por todo o exposto, apontaremos sempre as indústrias e corporaçôes mercantilistas da saúde com seus "achados extraordinários", lutaremos contra a criação de estigmas e rótulos nas pessoas, lutaremos contra o excesso diagnóstico e terapêutico, promovendo hábitos saudáveis pautados na ciência médica, livres de conflitos de interesses e de vieses de publicaçóes puramente deterministas ou causais, mas acima de tudo promovendo uma boa comunicação com as pessoas para que elas possam também aprender a se proteger do excesso de intervençôes em saúde. É nosso papel advogar pela legitimidade na relação profissional-paciente, reconhecendo as incertezas inerentes à ciência médica em si. Devemos orientar o cuidado de forma não normativa, apoiando-se em evidências isentas e permitindo o feedback do paciente, de modo que ele possa interpretar e ajustar a decisão para si enquanto protagonista do seu cuidado.

Curitiba, novembro de 2013.

\section{Referências}

1. Conselho Federal de Medicina (BR). Resolução №. 1931, de 24 de setembro de 2009. Aprova o código de ética médica. Diário Oficial da União. 2009 Sep 24; Seção 1:90-2.

2. Downie R. Professions and professionalism. J Philos Educ. 1990;24(2):147-159. Disponível em: http://dx.doi.org/10.1111/j.1467-9752.1990.tb00230.x

3. Jamoulle M, Roland M. Quaternary prevention. Paper presented at: WICC annual workshop Hong Kong. Hong Kong: Hong Kong Wonca Classification Committee; 1995.

4. Beauchamp TL, Childress JF. Principles of Biomedical Ethics. 4ed. New York: Oxford University Press; 1994.

5. Kuehlein T, Sghedoni D, Visentin G, Gérvas J, Jamoulle M. Quaternary prevention: a task of the general practitioner. Primary Care. 2010 [acesso em 2013 Dec 14];18(18):330-4. Disponível em: http://www.primary-care.ch/docs/primarycare/archiv/fr/2010/2010-18/2010-18-368_ELPS_engl.pdf

6. Mangin D, Toop L. The Quality and Outcomes Framework: what have you done to yourselves? Br J Gen Pract. 2007 June 1 [acesso em 2013 Dec 14]; 57(539):435-437. PMC2078175. Disponível em: http://www.ncbi.nlm.nih.gov/pmc/articles/PMC2078175/pdf/bjpg57-435.pdf 
